Article

\title{
Evaluation of Adhesive Characteristics of L. plantarum and $L$. reuteri Isolated from Weaned Piglets
}

\author{
Matteo Dell'Anno ${ }^{1}\left(\mathbb{D}\right.$, Carlotta Giromini ${ }^{1, *(\mathbb{D})}$, Serena Reggi ${ }^{1}{ }^{(\mathbb{D}}$, Mariagrazia Cavalleri ${ }^{1}$, Alessandra Moscatelli ${ }^{2}$, \\ Elisabetta Onelli ${ }^{2}{ }^{\circ}$, Raffaella Rebucci ${ }^{1}$, Tamil Selvi Sundaram ${ }^{1}$, Simona Coranelli ${ }^{3}$, Ambra Spalletta ${ }^{3}$, \\ Antonella Baldi ${ }^{1}$ and Luciana Rossi ${ }^{1}$ (D) \\ 1 Department of Health, Animal Science and Food Safety "Carlo Cantoni” (VESPA), \\ Università Degli Studi di Milano, 26900 Lodi, Italy; Matteo.DellAnno@unimi.it (M.D.); \\ serena.reggi@unimi.it (S.R.); mariagrazia.cavalleri@studenti.unimi.it (M.C.); raffaella.rebucci@unimi.it (R.R.); \\ tamil.sundaram@unimi.it (T.S.S.); antonella.baldi@unimi.it (A.B.); luciana.rossi@unimi.it (L.R.) \\ 2 Department of Biosciences, Università Degli Studi di Milano, 20133 Milan, Italy; \\ alessandra.moscatelli@unimi.it (A.M.); elisabetta.onelli@unimi.it (E.O.) \\ 3 Biotecnologie B.T. Srl, Todi, 06059 Perugia, Italy; scoranelli@biotecnologiebt.it (S.C.); \\ aspalletta@biotecnologiebt.it (A.S.) \\ * Correspondence: carlotta.giromini@unimi.it
}

Citation: Dell'Anno, M.; Giromini, C.; Reggi, S.; Cavalleri, M.; Moscatelli, A.; Onelli, E.; Rebucci, R.; Sundaram, T.S.; Coranelli, S.; Spalletta, A.; et al. Evaluation of Adhesive

Characteristics of L. plantarum and $L$. reuteri Isolated from Weaned Piglets. Microorganisms 2021, 9, 1587. https:// doi.org/10.3390/microorganisms 9081587

Academic Editor: Barbara

U. Metzler-Zebeli

Received: 9 June 2021

Accepted: 22 July 2021

Published: 26 July 2021

Publisher's Note: MDPI stays neutral with regard to jurisdictional claims in published maps and institutional affiliations.

Copyright: (c) 2021 by the authors. Licensee MDPI, Basel, Switzerland. This article is an open access article distributed under the terms and conditions of the Creative Commons Attribution (CC BY) license (https:/ / creativecommons.org/licenses/by/ $4.0 /)$.
Abstract: Limosilactobacillus reuteri and Lactiplantibacillus plantarum strains, previously isolated from weaned piglets, were considered for the evaluation of their adhesive characteristics. Lactobacilli were treated with $\mathrm{LiCl}$ in order to remove the surface protein layer, and probiotic activity was compared with those of untreated strains. The autoaggregation, co-aggregation to E. coli F18+, and adhesive abilities of LiCl-treated Limosilactobacillus reuteri and Lactiplantibacillus plantarum were significantly inhibited $(p<0.05)$ compared with the respective untreated strain. The hydrophobic and basic phenotypes were observed due to the strong affinity to chloroform and low adherence to ethyl acetate. In particular, L. plantarum showed higher hydrophobicity compared to L. reuteri, which may reflect their different colonizing ability. After treatment with $\mathrm{LiCl}$ to remove surface proteins, the adherence capabilities of L. reuteri and L. casei on IPEC-J2 cells decreased significantly $(p<0.001)$ and L. reuteri adhered more frequently. Sodium dodecyl sulphate-polyacrylamide gel electrophoresis (SDS-PAGE) showed that both L. reuteri and L. plantarum had several bands ranging from 20 to $100 \mathrm{kDa}$. Two-dimensional gel electrophoresis showed an acidic profile of the surface-layer polypeptides for both bacterial strains, and more studies are needed to characterize their profile and functions. The results confirm the pivotal role of surface proteins in the probiotic potential of L. reuteri and L. plantarum.

Keywords: probiotic; surface proteins; intestinal adhesion; gastro-intestinal system; E. coli; F18; pig; Lactobacillus plantarum; Lactobacillus reuteri; IPEC-J2

\section{Introduction}

Lactobacilli are part of the common flora in the porcine digestive tract [1]. Niu et al. [2] showed that the Lactobacillus genus accounts for approximately $15 \%$ of $16 \mathrm{~S}$ rRNA in intestinal pig samples, regardless of age. Notably, while the swine faecal microbiota changed significantly across growth stages, the populations of lactobacilli remain almost stable.

Although several studies have shown the positive impact of Limosilactobacillus reuteri and Lactiplantibacillus plantarum, previously known as the Lactobacillus genus, on piglet's performance improvement, diarrhoea prevention, stress alleviation, immunity, microbiota modulation, and carcass quality [3,4], they are not listed in the European register of additives for pigs. Moreover, the species- and strain-specific characteristics of lactobacilli that confer probiotic benefits are still not well-documented. Indeed, L. plantarum can be found in the European Register of Feed Additives according to European Regulation [5], under 
the categories of preservatives, silage additives, microorganisms, and gut flora stabilizers for fattening chickens. On the other hand, L. reuteri is mostly used as a probiotic in humans. Lactobacilli are generally selected as potential probiotics due to their natural ability to survive the digestive process. After the arrival in the intestinal section, lactobacilli can protect the host from pathogens by means of different mechanisms (competitive exclusion, bacteriocins production and stimulation of mucosal immunity) [6,7]. The adhesive capacity of bacteria to epithelial cells is one of the main probiotic characteristics [8]. The lactobacilli are Gram-positive bacteria characterized by a cell envelope consisting of a cell membrane and cell wall. These two layers are covered by several surface proteins, with the main function being as a protective sheath against environmental challenges. It has been previously proposed that bacteria surface proteins of lactobacilli are involved in cell protection and surface recognition and that they could be potential mediators of bacteria autoaggregation and adhesion to intestinal cells [9].

$L$. reuteri and $L$. plantarum were previously demonstrated to have a significant role in controlling diarrhoea in piglets [10]. In particular, dietary supplementation of $2 \times 10^{8} \mathrm{CFU} / \mathrm{g}$ of $L$. plantarum and $L$. reuteri significantly reduced diarrhoea occurrence and had the lowest faecal score in our trial. L. plantarum showed the lowest diarrhoea frequency compared to the other bacterial strains and their combinations. L. plantarum and L. reuteri supplementation did not influence animal performance, total faecal bacteria, faecal lactobacilli and coliform. In addition, L. plantarum and L. reuteri showed high resistance to a wide range of $\mathrm{pH}$ and digestive processes [10]. In our attempt to study the adhesive characteristics in the probiotic activity of L. reuteri and L. plantarum, we investigated Limosilactobacillus reuteri and Lactiplantibacillus plantarum autoaggregation, co-aggregation capacity to Escherichia coli F18+, bacterial hydrophobicity, adhesion to swine intestinal IPEC-J2 cells and cell surface proteins characteristics.

\section{Materials and Methods}

\subsection{Bacterial Strains and Culturing Conditions}

Single colonies of L. plantarum and L. reuteri, isolated from swine, were obtained from the Biotecnologie B.T. (Perugia, Italy) strain collection [10] and grown in MRS agar medium. L. plantarum and L. reuteri strains were individually inoculated from our laboratory stock at $-80{ }^{\circ} \mathrm{C}$ into the De Man, Rogosa and Sharpe (MRS) medium (Liofilchem, Italy) and incubated at $35^{\circ} \mathrm{C}$ for $24 \mathrm{~h}$ under a microaerophilic atmosphere by adding sterile oil above the culture media.

\subsection{Aggregative Abilities of LAB Strains}

Lactobacilli were cultured in MRS broth at $35^{\circ} \mathrm{C}$ for $24 \mathrm{~h}$ under a microaerophilic atmosphere by adding sterile oil above the culture media. Bacterial pellets were harvested by centrifugation (3500 rpm, $10 \mathrm{~min}$ ), and cells were rinsed with PBS (1X) in order to reach an optical density (OD) of $0.2-0.3$ at $600 \mathrm{~nm}$ wavelength using a spectrophotometer (Jasco V630 UV-VIS, JASCO Deutschland GmbH, Pfungstadt, Germany). Cell suspensions were vortexed for $6 \mathrm{~s}$ and incubated $6 \mathrm{~h}$ at room temperature. On millilitre of the upper part of the suspension was measured at $600 \mathrm{~nm}$ each hour. The percentage of auto-aggregation was then calculated.

$$
\% \text { autoaggregation }=\left[1-\left(\frac{\mathrm{At}}{\mathrm{A} 0}\right)\right] \times 100
$$

where At is the absorbance at different time points and $\mathrm{A} 0$ the initial one.

For co-aggregation abilities, resuspended LAB strains were mixed with aliquots of F18+ E. coli previously characterized for the presence of F18 adhesive fimbriae [11]. The E. coli culture was obtained by incubating the bacterial strain at $37^{\circ} \mathrm{C}$ in Luria-Bertani medium under aerophilic conditions, and to left stir overnight at $110 \mathrm{rpm}$. Samples were mixed thoroughly for $10 \mathrm{~s}$ and incubated for $6 \mathrm{~h}$ at room temperature. One millilitre of 
the upper part of the suspension was measured at $600 \mathrm{~nm}$ each hour. The co-aggregation percentage was then calculated.

$$
\% \text { coaggregation }=\left\{\frac{\left[\left(\frac{\mathrm{Ax}+\mathrm{Ay}}{2}\right)-\mathrm{A}(\mathrm{x}+\mathrm{y})\right]}{\mathrm{Ax}+\mathrm{Ay} / 2}\right\} \times 100
$$

Ax and Ay indicate the individual proprieties of lactobacilli and E. coli, and $\mathrm{A}(\mathrm{x}+\mathrm{y})$ express the combined aggregation of L. plantarum or L. reuteri and E. coli. The whole analyses were performed in two independent experiments including three replicates.

\subsection{Determination of Bacterial Hydrophobicity}

Microbial adhesion to solvents (MATS) was assessed according to Kos et al. [12]. Briefly, bacteria were harvested from the stationary phase after centrifugation $(5000 \times g$ for $15 \mathrm{~min})$. Samples were washed twice and resuspended in PBS (1X, pH 7.0) and brought to OD 0.6 at $600 \mathrm{~nm}$. For the assay, $1 \mathrm{~mL}$ of the solvent was added to $3 \mathrm{~mL}$ of the bacterial suspension. After $10 \mathrm{~min}$ as preincubation at room temperature, samples were mixed for $2 \mathrm{~min}$. After $20 \mathrm{~min}$, the aqueous phase was removed to measure the OD at $600 \mathrm{~nm}$ (A1). The percentage of bacterial surface hydrophobicity was then calculated.

$$
\left(\frac{\text { Absorbance before mixing }- \text { Absorbance after mixing }}{\text { Absorbance before mixing }}\right) \times 100
$$

For the evaluation of surface hydrophobicity, three solvents were tested: toluene (Titolchimica, Italy) as the apolar solvent; chloroform (Merck, Darmastadt, Germany) as monopolar basic and acidic solvent; and ethyl acetate (Carlo Erba Reagents S.A.S, Milan, Italy) as monopolar basic solvent [13]. The whole analyses were performed in two independent experiments including three replicates.

\subsection{Cell Line and Culture Conditions}

IPEC-J2 is a non-transformed cell line, derived from the jejunum epithelium of unsuckled piglets (DSMZ, Braunschweig, Germany). Cells used for the experiment were defrosted from a cryopreserved stock and cell passages of 24-28 were used for the experiments. Cells were routinely grown in a total volume of $100 \mathrm{~mL}$ of 1:1 of Dulbecco's modified Eagle's medium with stable L-glutamate and Ham's F-12 mixture (DMEM/F12) (Immunological sciences, Società Italiana Chimici, Rome, Italy), plus 15 mM of HEPES (Sigma-Aldrich, Milano, Italy), 5\% heat-inactivated foetal bovine serum (FBS) (Immunological sciences, Società Italiana Chimici, Rome, Italy), 1\% penicillin $(100 \mathrm{U} / \mathrm{mL}) /$ streptomycin $(100 \mathrm{mg} / \mathrm{mL})$ (Euroclone, Milano, Italy) and $1 \%$ GlutaMAX at $37{ }^{\circ} \mathrm{C}$ in a $5 \% \mathrm{CO}_{2}$ atmosphere and subcultivated at $80 \%$ confluence. For adhesion assay, IPEC-J2 monolayers were prepared in a 2-well chamber slides system coated with collagen. After collagen coating, the cells were seeded at a concentration of $4 \times 10^{5}$ cells / chamber to reach $80 \%$ confluence before lactobacilli addition.

\subsection{Bacterial Adhesion Assay}

Two-well chamber slides were used to study the adhesion ability of L. plantarum, L. reuteri and L. casei ATCC 393 (reference strain) to IPEC-J2 cells. Two millilitres of $48 \mathrm{~h}$ cultures of L. plantarum, L. reuteri and L. casei grown in $30 \mathrm{~mL}$ MRS broth (adjusted to $2.3 \times 10^{8} \mathrm{CFU} / \mathrm{mL}$ ) were centrifuged, washed, and resuspended in DMEM/F12 medium. Before the experiments, the cell medium was removed and $1 \mathrm{~mL}$ of each bacterial suspension was added to one well of each chamber slide, while the other well was filled with $1 \mathrm{~mL}$ of each bacterial suspension after $\mathrm{LiCl}(5 \mathrm{M})$ treatment [14]. Briefly, the cell pellet was resuspended in $\mathrm{LiCl}(5 \mathrm{M})$ and incubated at room temperature for $30 \mathrm{~min}$. Bacteria were centrifugated at $5000 \times g$ for $15 \mathrm{~min}$, and the cell pellet was washed twice with sterile saline solution before being resuspended in the cell medium. After $1 \mathrm{~h}$ incubation in a $5 \%$ 
$\mathrm{CO}_{2}$ atmosphere, the chamber slides were washed twice with PBS (1X) with Ca and $\mathrm{Mg}$, and a $15 \mathrm{~min}$ fixation step with $500 \mu \mathrm{L}$ of MetOH was made. Then, GIEMSA staining was performed with the GIEMSA dye diluted at a ratio of 1:20 with PBS (1X) for $30 \mathrm{~min}$. After washing with deionized water, the glasses were left to dry overnight. Cells and bacteria in a 20 microscopy field $(100 \times$ magnification with oil immersion) were randomly counted; the bacteria adherent to at least 200 cells were counted. The analyses were performed in three independent experiments including at least two technical replicates per treatment. The bacterial adherence value was defined as the number of the adhered bacteria per cell [15]. Data are expressed as adherent bacteria/number of cells.

\subsection{Isolation and One and Two-Dimensional Gel Electrophoresis of S-Layer Proteins from L. plantarum and L. reuteri}

S-layer proteins of lactobacilli were extracted by $5 \mathrm{M} \mathrm{LiCl}$ according to the method reported by Singh et al. [16]. Briefly, lactobacilli were incubated in $30 \mathrm{~mL}$ MRS at $35^{\circ} \mathrm{C}$ in anaerobiosis conditions. Cells were collected and washed twice with sterile water. The pellet was treated with $5 \mathrm{M} \mathrm{LiCl}$ at $4{ }^{\circ} \mathrm{C}$ for $30 \mathrm{~min}$. The supernatant was collected and dialyzed with PBS (1X) and concentrated. The extracted surface proteins were quantified using the Bradford method, with bovine serum albumin (BSA) as the standard [17]. For determination of the apparent molecular mass, SDS-PAGE was performed using a 10\% $(w / v)$ acrylamide gel in denaturing and reducing conditions. The gel was stained by Coomassie brilliant blue R-250 (Sigma, Saint Louis, MO, USA) and the intensity of bands was evaluated using ImageJ software. For two-dimensional gel electrophoresis, $25 \mu \mathrm{g}$ of extracted S-layer proteins were precipitated with cold ethanol $(1: 5 \mathrm{v} / \mathrm{v})$ and incubated for $30 \mathrm{~min}$ in ice. The pellet was obtained by centrifugation at $4{ }^{\circ} \mathrm{C}$ for $36 \mathrm{~min}$ at $20,627 \mathrm{~g}(15,000 \mathrm{rpm})$ in an ALC A21-C rotor. Ethanol was removed and the pellet was resuspended with 2D $200 \mu \mathrm{L}$ of rehydration buffer ( $8 \mathrm{M}$ urea, $4 \%$ CHAPS, $65 \mathrm{mM}$ dithioerythritol, $0.5 \%$ bromophenol blue) supplemented with 2\% 3-10 IPG buffer and loaded onto 7-cm non-linear $\mathrm{pH} 3-10$ strips by overnight passive rehydration at room temperature. IEF was performed with Multifor II system (GE Healthcare, Chicago, IL, USA) according to Moscatelli et al. [18] (200 V for $1 \mathrm{~h}$, $2000 \mathrm{~V}$ for $3 \mathrm{~h}$ and $3000 \mathrm{~V}$ for $3 \mathrm{~h}$ and $30 \mathrm{~min}$ ). Focused strips were equilibrated in Buffer I (0.5 M TrisHCl, pH 6.8, 2\% SDS, $6 \mathrm{M}$ urea, 30\% glycerol, 2\% DTE) for $12 \mathrm{~min}$ and then for another $5 \mathrm{~min}$ in Buffer II (composition the same as Buffer I, but with 2.5\% iodoacetamide instead of DTE) at room temperature. SDS-PAGE was run in $10 \%$ polyacrylamide gel (MiniVe Vertical Electrophoresis System, GE Healthcare, Chicago, IL, USA), as described previously [19]. The gels were silver-stained [20].

\subsection{Statistical Analysis}

The statistical analyses were performed through the software GraphPad Prism 9.0.1. The results of the aggregation, co-aggregation, cell surface hydrophobicity and adhesion assay for both the species were analysed through a one-way analysis of variance (ANOVA) procedure. Pairwise comparisons were evaluated using Tukey's HSD test. Differences were considered statistically significant at $p \leq 0.05$. Data were expressed as the least squares (LS) means \pm standard error of mean (SEM).

\section{Results}

\subsection{Aggregation Abilities}

The auto-and co-aggregation abilities of the L. plantarum and L. reuteri are summarized in Figures 1 and 2. After $6 \mathrm{~h}$ of incubation, the highest percentages of aggregation were observed for $L$. reuteri. Both strains demonstrated co-aggregation ability with intestinal pathogen tested (E. coli F18+). The maximum autoaggregation and co-aggregation were shown by $L$ reuteri at $6 \mathrm{~h}(38.46 \pm 0.49 \%$ and $11.60 \pm 0.30 \%$, respectively). The autoaggregation and co-aggregation ability to $E$. coli $\mathrm{F} 18+$ of $L$. reuteri decreased significantly after $\mathrm{LiCl}$ treatment compared to the untreated strain $(p<0.05)$, while L. plantarum showed that $\mathrm{LiCl}$ treatment did not impair its co-aggregation ability to E. coli (Figure 3). 


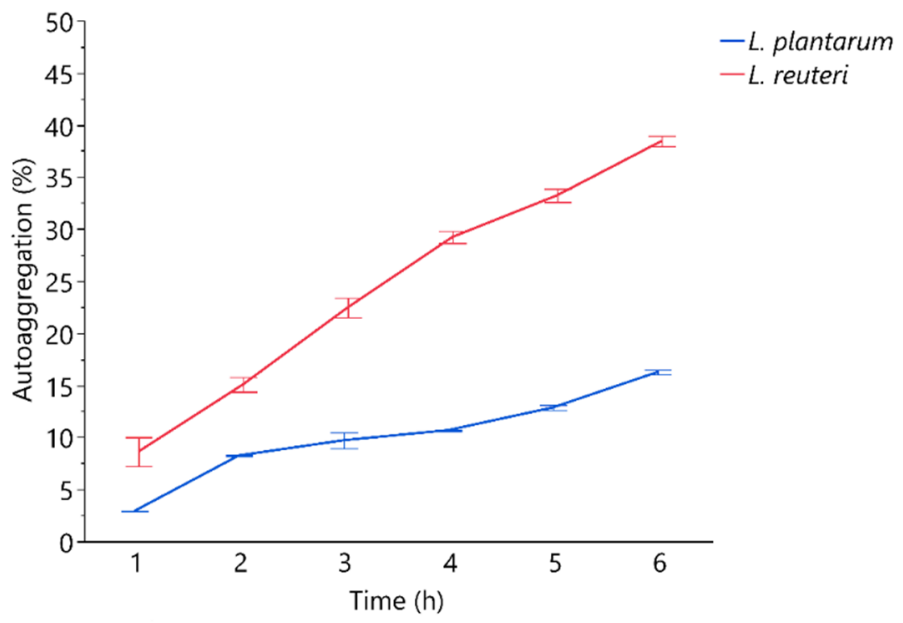

Figure 1. Percentages of autoaggregation measured at hourly bases. Data are presented as means \pm standard deviations.

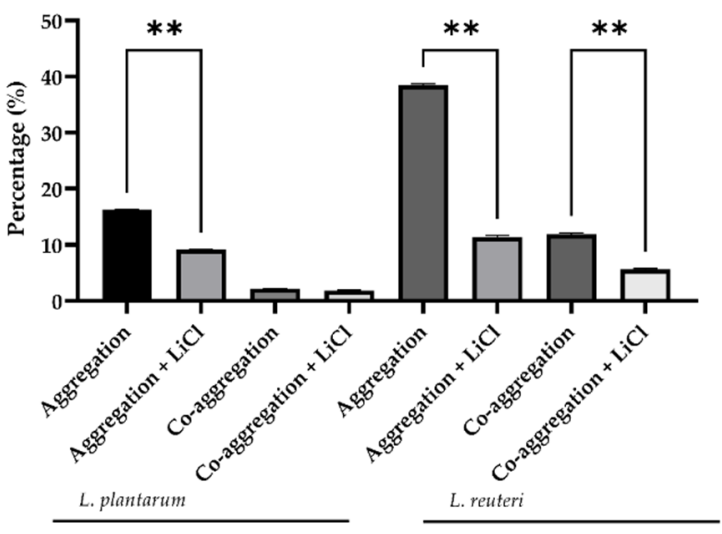

Figure 2. Percentage of L. reuteri and L. plantarum aggregation and co-aggregation with E. coli F18 measured at $6 \mathrm{~h}$. Data are presented as LS mean \pm SEM. ${ }^{* *}$ indicates a statistically significant difference $(p \leq 0.001)$.
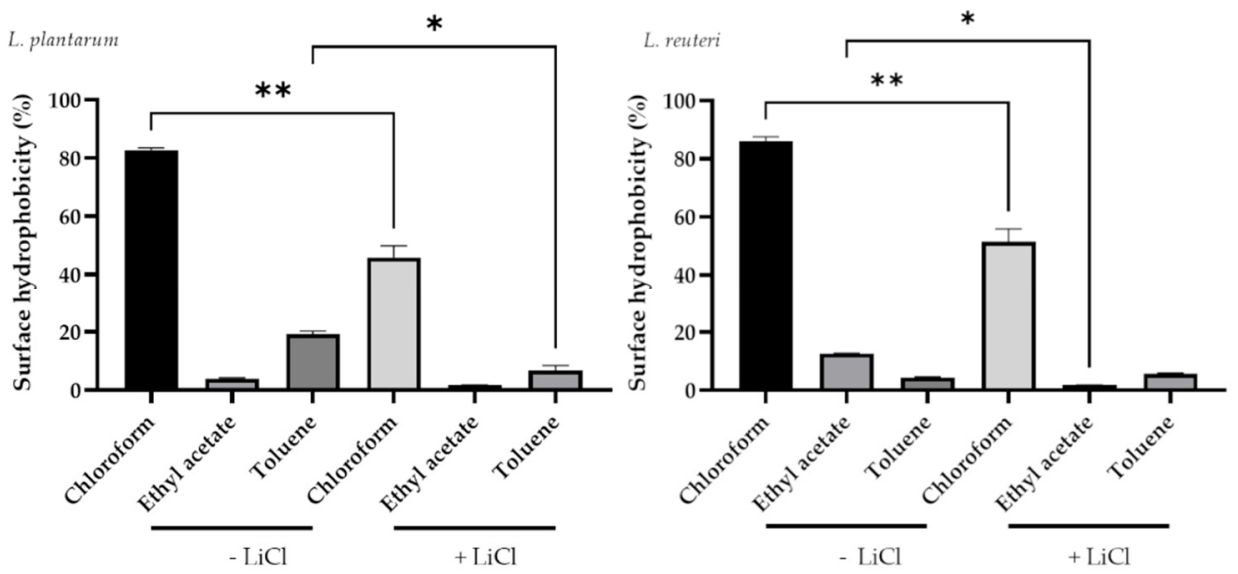

Figure 3. Effect of $\mathrm{LiCl}$ treatment on cell surface hydrophobicity of lactobacilli strains. Data are presented as LS means \pm SEM. * Indicates a statistically significant difference $(p \leq 0.05) ;{ }^{* *}$ indicates a statistically significant difference $(p \leq 0.001)$.

\subsection{Determination of Bacterial Hydrophobicity}

In particular, L. plantarum and L. reuteri showed a significant decrease in bacteria in the aqueous phase after a chloroform treatment $(82.83 \pm 1.29 \%$ for untreated and $49.65 \pm 1.45 \%$ for 
chloroform treated L. plantarum; $86.17 \pm 2.12$ for untreated and $55.22 \pm 1.25 \%$ for chloroform treated $L$. reuteri; $p<0.0001$ ) (Figure 3). The same drop was registered in the aqueous phase with toluene treatment for both bacterial strains $(19.20 \pm 1.69 \%$ for untreated and $6.91 \pm 1.76 \%$ for toluene treated L. plantarum; $5.47 \pm 1.28 \%$ for untreated and $1.94 \pm 0.21 \%$ for toluene treated L. reuteri; $p<0.05)$.

\subsection{Bacterial Adhesion Assay}

L. reuteri showed the greatest adhesion capacity compared with L. casei and L. plantarum (Figures 4 and 5). L. plantarum adhesion was not affected by the treatment with $\mathrm{LiCl}$ $(14.64 \pm 1.22$ versus $11.04 \pm 1.17)$. On the contrary, the treatment with $\mathrm{LiCl}$ significantly affected the adhesion capacity of $L$. reuteri and L. casei $(p<0.05)$. In particular, $16.77 \pm 1.82$ adherent bacteria/cell were counted in L. reuteri-treated cells while $8.63 \pm 1.08$ adherent bacteria/cell in L. reuteri + LiCl-treated cells. Regarding L. casei, $10.07 \pm 1.02$ adherent bacteria were counted in $L$. casei-treated cells whereas $5.14 \pm 0.74$ adherent bacteria in L. casei + LiCl-treated cells.
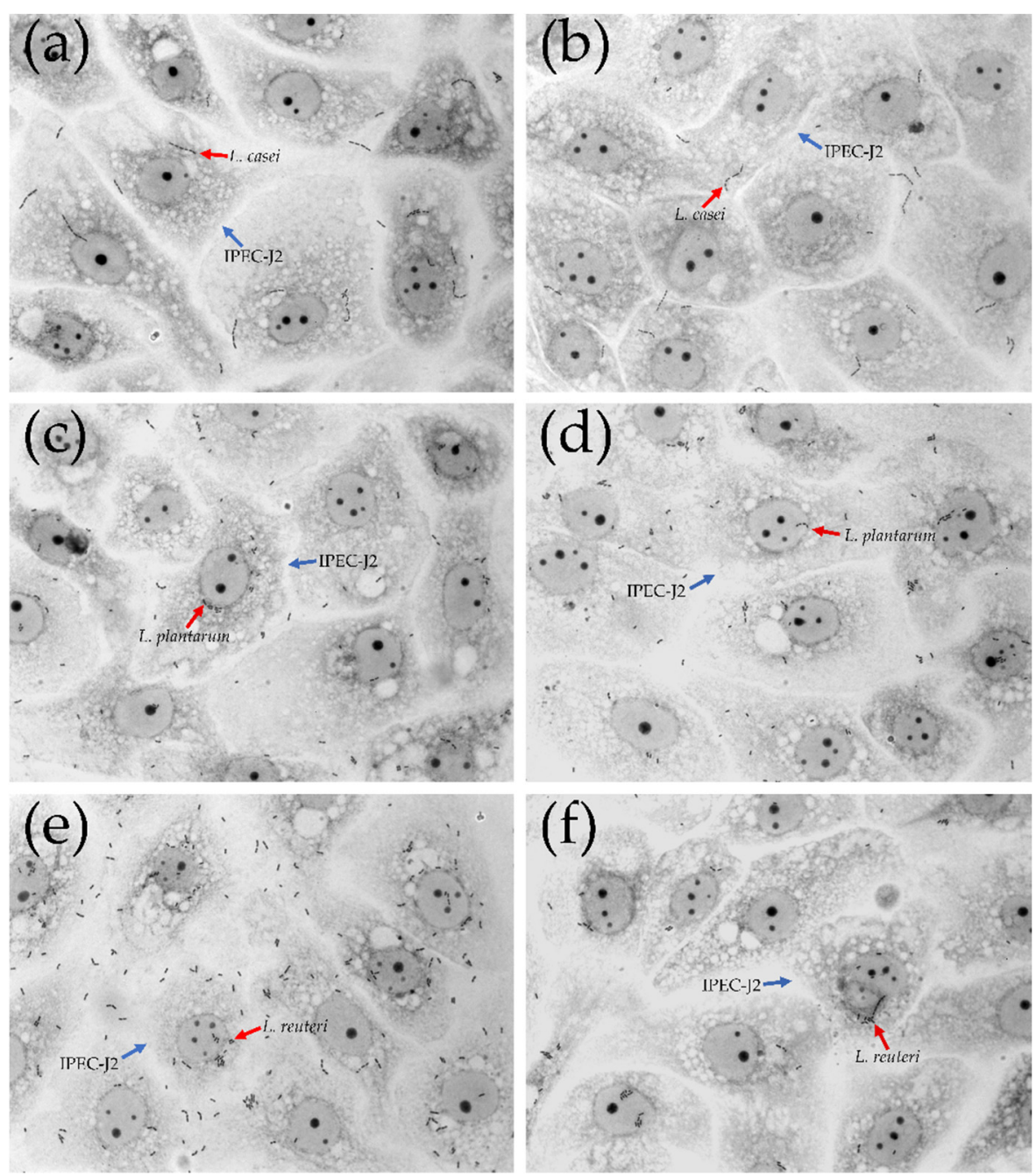

Figure 4. Adhesion of L. casei, L. plantarum and L. reuteri to IPEC-J2 cells. Representative microphotographs with $100 \times$ magnification (oil immersion). (a) L. casei; (b) L. casei $+\mathrm{LiCl}$; (c) L. plantarum; (d) L. plantarum $+\mathrm{LiCl} ;$ (e) L. reuteri; (f) L. reuteri $+\mathrm{LiCl}$. Red arrows indicate lactobacilli strains; blue arrows indicate IPEC-J2 cells. 


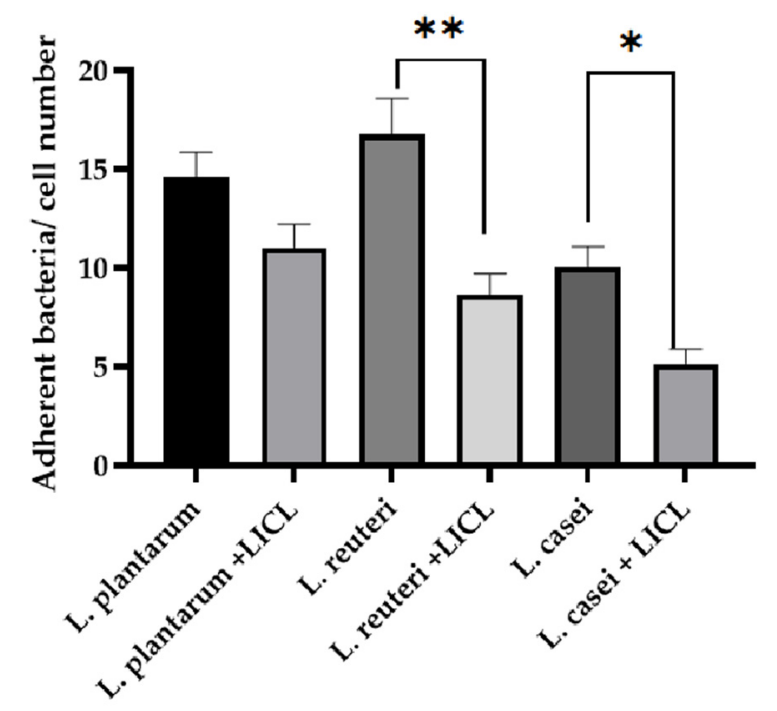

Figure 5. Count of adherent bacteria to IPEC-J2 cells, data are expressed as the mean value of adherent bacteria/cell number \pm SEM of three independent experiments. * indicates a statistically significant difference $(p \leq 0.05) ;{ }^{* *}$ indicates a statistically significant difference $(p \leq 0.001)$.

\subsection{One and Two-Dimensional Gel Electrophoresis of Surface Proteins from Lactobacilli Strains}

The extracted surface proteins resulted $1.478 \mu \mathrm{g} / \mathrm{mL}$ for L. plantarum and $0.970 \mu \mathrm{g} / \mathrm{mL}$ for L. reuteri, respectively.

One-dimensional denaturing gel revealed distinct protein bands, although quite qualitative differences in the intensity of bands of the surface proteins were observed (Figure S1). The observed polypeptides profile resulted in the range 20-100 kDa by comparison with the marker (Figure 6A). The two-dimensional gel electrophoresis did not show significant variations of protein spots between the two bacterial strains. The two-dimensional gel was mainly characterized by acid polypeptides ranging from 100 to $10 \mathrm{kDa}$ for L. plantarum and L. reuteri, and no clusters were detected (Figure 6B).
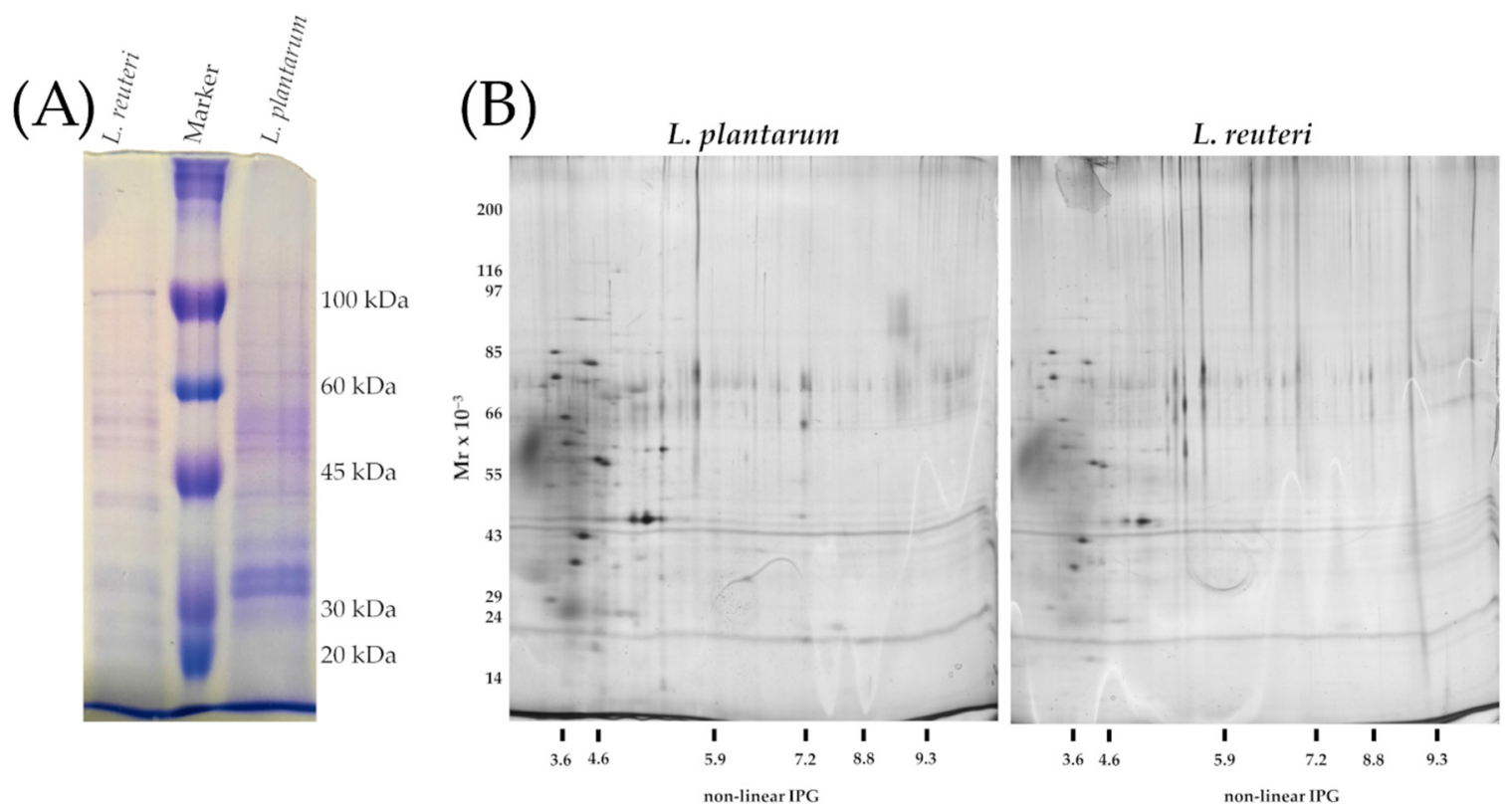

Figure 6. (A) SDS-PAGE of surface proteins. Equal amount of volume $(14 \mu \mathrm{L})$ of the extracted polypeptides were loaded to each well; from left to right: S-layer extracted from Lactobacillus reuteri; Molecular weight marker (kDa), S-layer extracted from Lactobacillus plantarum. (B) Two-dimensional gel electrophoresis of S-layer polypeptides extracted from L. plantarum and L. reuteri. 


\section{Discussion}

Alternatives to antibiotics are urgently needed due to the global concern regarding antibiotic resistance in livestock production systems [21-23].

Probiotics are defined as living microorganisms that can act in the treatment and prevention of infectious diseases when ingested in adequate amounts [24]. In particular, probiotic bacteria surface proteins have been demonstrated to intervene in cell protection and competitive adhesion against pathogens [9]. The presence of glyco-proteinaceous material at the bacterial cell surface is responsible of a higher hydrophobicity, whereas hydrophilic surfaces are associated with the presence of polysaccharides and affect the binding capabilities of probiotics [9]. In our study, a hydrophobic and basic phenotype of L. plantarum and L. reuteri was observed due to lactobacilli affinity to chloroform and ethyl acetate. In particular, L. plantarum showed higher hydrophobicity compared to L. reuteri, which may reflect their different colonizing ability. The values of MATS for toluene reflect the cell surface hydrophobicity or hydrophilicity capacities. Chloroform and ethyl acetate were used to assess their characteristics as electron donors (basic) and electron acceptors (acidic) of bacteria. In this study, the use of $\mathrm{LiCl}$ was adopted on probiotic cells to allow the selective and efficient removal of S-layer proteins. In particular, this step was carried out to evaluate the adhesive properties without surface proteins. Firstly, hydrophobic cell surfaces are reported for autoaggregation capacities that in some cases determine the intestinal colonization [25]. As expected, the treatment with $\mathrm{LiCl}$ strongly affected the hydrophobicity. The observed results suggest that $L$. plantarum and L. reuteri could potentially adhere to gut epithelium.

Other important characteristics of a probiotic bacteria are the auto- and co-aggregation capacity. The auto-aggregation is defined as the ability of cells of the same kind to self-adhere, and is recognized as an important predictive parameter for gut epithelium colonization as it allows bacteria to maintain a significant number of cells in the environmental niche [26]. Co-aggregation is defined as the binding of bacteria of diverse species (e.g., lactobacilli versus pathogens), and also evaluates the competitive inhibition capacity [26]. In fact, the formation of co-aggregates of lactobacilli with pathogens reduced pathogenic microorganisms' ability to adhere to the intestinal epithelium [27]. In the present study, the auto-aggregation and co-aggregation to E. coli F18+ capacity of L. plantarum and reuteri indicate that cell surface proteins could be associated with lactobacilli aggregation properties and to specific binding capabilities in the gastrointestinal tract. Moreover, co-aggregation has been recognized as an important factor in the establishment and maintenance of a non-infectious gastrointestinal microflora. The observed co-aggregation with E. coli of L. reuteri and L. plantarum could suggest that lactobacilli constitute an important host-defence mechanism against infection. This hypothesis was also confirmed by the in vivo results described by Dell'Anno et al. [10], that registered a significative reduction in diarrhoea occurrence in weaned piglets' diets supplemented with the investigated L. plantarum and L. reuteri strains. In this study, we focused on Escherichia coli F18+, a widely spread porcine enterotoxigenic pathogen, responsible for important economic losses in the pig industry $[28,29]$. E. coli F18+ strain has the ability to adhere to the intestinal surface by F18 adhesive fimbriae, and it is considered a major pathogen involved in the post-weaning disease and oedema disease [30]. Our study suggests that L. plantarum and L. reuteri can compete for adhesion with a pathogenic strain of $E$. coli through the formation of a barrier via auto-aggregation of by directly by co-aggregation with E. coli. It is recognized that auto-aggregation ability is related to adhesive properties of bacterial strains [31].

IPEC-J2 cell model is commonly used to investigate lactobacilli strains adhesive capacities [32]. The porcine intestinal epithelial IPEC-J2 cell line provides an excellent in vitro model for probiotic adhesion studies [33]. IPEC-J2 have been largely studied to assess probiotic adhesive properties and the anti-inflammatory activity of probiotic strains [34]. As shown by Tallon et al. [35], different chemical pre-treatments may influence the adhesive capacities of bacteria depending on the surface proteins that are involved in 
the adhesion process. In line with the study of Singh et al. $[9,16]$, the pre-treatment with $\mathrm{LiCl}$ to remove cell surface proteins reduced the ability of $L$. reuteri to adhere to intestinal epithelium. On the contrary, L. plantarum was more resistant to $\mathrm{LiCl}$ treatment, probably due to the structural variations existing between the microorganism-associated molecular patterns which interact with the host pattern recognition receptors [36]. In this study, L. reuteri showed a higher adhesion ability compared to the behaviour of $L$. casei used as a control strain, in accordance with the study by Lähteinen et al. [37], which observed that $L$. reuteri isolates from the porcine intestine revealed the greatest adhesion capacity compared to other commensal lactobacilli in swine GIT (L. amylovorus, L. mucosae and L. johnsonii). In addition, specific strains of $L$. reuteri express different surface proteins capable of improving binding properties compared with a well-known probiotic such as L. casei [31,38-40]. Mucus binding abilities related to the production of mannose-sensitive adhesins have been reported for some L. plantarum and L. reuteri strains [25]. The observed adhesion properties could be due to the presence of mucus-binding proteins on cell surface of these two bacteria.

In line with other studies, the SDS-PAGE of cell surface proteins of L. reuteri and L. plantarum revealed the presence of several bands of varying length if compared with the protein fragments of the marker in the range from 100 to $20 \mathrm{kDa}[9,41]$. Two-dimensional gel electrophoresis confirmed the acidic prevalence of bacterial surface proteins that are typical subunits of surface proteins of lactobacilli [42]. In visual evaluation, the polypeptide profile was very similar, and the molecular range confirmed the previously observed results of one-dimensional electrophoresis (SDS-PAGE). In line with our results, Wang et al. [41] observed that a protein of approximately $37 \mathrm{kDa}$ for L. plantarum strain. This protein, the glyceraldehyde-3phospated dehydrogenase (GAPDH), plays an important role for the adhesion properties of L. plantarum [41]. It has been shown that CscA, CscB and CscD proteins of L. plantarum are functionally related to a cell-surface protein complex that could play a role in sugar acquisition. In particular, a $\csc B$ gene product known as co-aggregation-promoting factor ( $\mathrm{Cpf}$ ) could be removed from L. plantarum surface by treating bacterial cells with $\mathrm{LiCl}(5 \mathrm{M})$ and reattached by salt removal, restoring its co-aggregation ability [43]. Mannose-binding proteins of L. plantarum WCFS1 are similar to a mucus-binding protein from $L$. reuteri that are likely to be involved in the interaction with the host [44]. L. reuteri 100-23 possesses a high-molecular-mass surface protein (Lsp) and methionine sulfoxide reductase $B(\mathrm{MsrB})$, which both contribute to adherence in the gut [45]. L. reuteri JCM1081's adhesive property appeared to be mediated by the presence of a surface protein of approximately $29 \mathrm{kDa}$ with an important similarity to the putative ATP-binding cassette transported protein CnBP [46]. In our study, L. plantarum and L. reuteri revealed a quite similar surface profile, with polypeptides ranging from 20 to $100 \mathrm{kDa}$; however, their characterization and functions need to be confirmed by further experiments.

The survival of probiotics during gastrointestinal transit and their adhesion on the intestinal surface are important prerequisites for the colonization and competitive inhibition proprieties. The strains here analysed have been previously demonstrated to greatly survive the gastro-intestinal conditions [10], which is an important prerequisite in probiotic efficacy. The results here presented clearly indicate the relation between cell surface characteristics and adhesion ability of L. reuteri and L. plantarum. Therefore, more studies are needed to identify the particular proteins involved in these mechanisms, in order to select the most suitable probiotic strains for application in weaning piglets. The findings of the current study can be extrapolated to those situations in which it could be relevant to formulate a probiotic product to target performance or health-related challenges in the pig's life.

\section{Conclusions}

Our study showed that $\mathrm{LiCl}$ significantly inhibited the autoaggregation and coaggregation to E. coli of L. plantarum and L. reuteri. In addition, a strong affinity to chloroform indicated the hydrophobic and basic phenotypes of these lactobacilli. The adhesive capacity of $L$. reuteri on IPEC-J2 cells was significantly reduced after a pre-treatment with 
$\mathrm{LiCl}$, suggesting a pivotal role of surface proteins in the epithelial adhesion. L. plantarum and $L$. reuteri revealed an important influence of the adhesive proteins related to their probiotic characteristics, further research is necessary to better address the mechanisms of these proteins in the gut colonization, and also in relation to intestinal microbiota. Additionally, L. plantarum and L. reuteri might be suitable candidates for further study, due to their protective effects against $E$. coli infections in weaned piglets.

Supplementary Materials: The following are available online at https://www.mdpi.com/article/10 $.3390 /$ microorganisms9081587/s1.

Author Contributions: Conceptualization, C.G., S.R. and L.R.; methodology, C.G. and S.R.; formal analysis, S.R., R.R., M.C., M.D., A.S., S.C., T.S.S., A.M. and E.O.; investigation, C.G., S.R., M.D., M.C., T.S.S., A.M. and E.O.; data curation, S.R., C.G., M.D. and M.C.; writing-original draft preparation, C.G., S.R., M.C. and M.D.; writing-review and editing, A.S., S.C., R.R., A.M., E.O. and L.R.; visualization, C.G., A.M. and M.D.; supervision, A.B.; project administration, L.R.; funding acquisition, L.R. All authors have read and agreed to the published version of the manuscript.

Funding: This research was funded by Lombardy Region and European Regional Development Fund (ERDF) under grant: FoodTech Project (ID: 203370).

Institutional Review Board Statement: The study was conducted according to the guidelines of the Declaration of Helsinki.

Informed Consent Statement: Not applicable.

Data Availability Statement: The data presented in this study are available within the article.

Acknowledgments: We are grateful to ProPhos Chemicals S.r.l. for project coordination. The authors acknowledge the University of Milan for the support through the APC initiative.

Conflicts of Interest: The authors declare no conflict of interest.

\section{References}

1. Valeriano, V.D.; Balolong, M.; Kang, D.-K.; Valeriano, V.D.; Balolong, M.; Kang, D.-K. Probiotic roles of Lactobacillus sp. in swine: Insights from gut microbiota. J. Appl. Microbiol. 2017, 122, 554-567. [CrossRef]

2. Niu, Q.; Li, P.; Hao, S.; Zhang, Y.; Kim, S.W.; Li, H.; Ma, X.; Gao, S.; He, L.; Wu, W. Dynamic distribution of the gut microbiota and the relationship with apparent crude fiber digestibility and growth stages in pigs. Sci. Rep. 2015, 5, 1-7. [CrossRef]

3. Hou, C.; Zeng, X.; Yang, F.; Liu, H.; Qiao, S. Study and use of the probiotic Lactobacillus reuteri in pigs: A review. J. Anim. Sci. Biotechnol. 2015, 6, 1-8. [CrossRef]

4. Wang, W.; Chen, J.; Zhou, H.; Wang, L.; Ding, S.; Wang, Y.; Song, D.; Li, A. Effects of microencapsulated Lactobacillus plantarum and fructooligosaccharide on growth performance, blood immune parameters, and intestinal morphology in weaned piglets. Food Agric. Immunol. 2017, 29, 84-94. [CrossRef]

5. Regulation EC 1831/2003. of the European Parliament and of the Council, of 22 September 2003 on Additives for Use in Animal Nutrition (Text with EEA Relevance); Official Journal of the European Union: Brussels, Belgium, 2003.

6. Walter, J. Ecological Role of Lactobacilli in the Gastrointestinal Tract: Implications for Fundamental and Biomedical Research. Appl. Environ. Microbiol. 2008, 74, 4985-4996. [CrossRef]

7. Hekmat, S.; Soltani, H.; Reid, G. Growth and survival of Lactobacillus reuteri RC-14 and Lactobacillus rhamnosus GR-1 in yogurt for use as a functional food. Innov. Food Sci. Emerg. Technol. 2009, 10, 293-296. [CrossRef]

8. Van Tassell, M.L.; Miller, M.J. Lactobacillus Adhesion to Mucus. Nutrients 2011, 3, 613-636. [CrossRef] [PubMed]

9. Singh, T.P.; Malik, R.K.; Kaur, G. Cell surface proteins play an important role in probiotic activities of Lactobacillus reuteri. Nutrire 2016, 41, 1-10. [CrossRef]

10. Dell'Anno, M.; Callegari, M.L.; Reggi, S.; Caprarulo, V.; Giromini, C.; Spalletta, A.; Coranelli, S.; Rossi, C.A.S.; Rossi, L. Lactobacillus plantarum and Lactobacillus reuteri as Functional Feed Additives to Prevent Diarrhoea in Weaned Piglets. Animals 2021, 11, 1766. [CrossRef] [PubMed]

11. Dell'Anno, M.; Sotira, S.; Rebucci, R.; Reggi, S.; Castiglioni, B.; Rossi, L. In vitro evaluation of antimicrobial and antioxidant activities of algal extracts. Ital. J. Anim. Sci. 2020, 19, 103-113. [CrossRef]

12. Kos, B.; Šušković, J.; Vuković, S.; Šimpraga, M.; Frece, J.; Matošić, S. Adhesion and aggregation ability of probiotic strain Lactobacillus acidophilus M92. J. Appl. Microbiol. 2003, 94, 981-987. [CrossRef] [PubMed]

13. Bellon-Fontaine, M.-N.; Rault, J.; Van Oss, C. Microbial adhesion to solvents: A novel method to determine the electrondonor/electron-acceptor or Lewis acid-base properties of microbial cells. Colloids Surf. B Biointerfaces 1996, 7, 47-53. [CrossRef]

14. Zhang, W.; Wang, H.; Liu, J.; Zhao, Y.; Gao, K.; Zhang, J. Adhesive ability means inhibition activities for lactobacillus against pathogens and S-layer protein plays an important role in adhesion. Anaerobe 2013, 22, 97-103. [CrossRef] [PubMed] 
15. Guan, C.; Chen, X.; Jiang, X.; Zhao, R.; Yuan, Y.; Chen, D.; Zhang, C.; Lu, M.; Lu, Z.; Gu, R. In vitro studies of adhesion prop-erties of six lactic acid bacteria isolated from the longevous population of China. RSC Adv. 2020, 10, 24234-24240. [CrossRef]

16. Singh, T.P.; Kaur, G.; Kapila, S.; Malik, R.K. Antagonistic activity of Lactobacillus reuteri strains on the adhesion characteristics of selected pathogens. Front. Microbiol. 2017, 8, 486. [CrossRef] [PubMed]

17. Bonjoch, N.P.; Tamayo, P.R. Protein Content Quantification by Bradford Method. In Handbook of Plant Ecophysiology Techniques; Springer: Berlin/Heidelberg, Germany, 2006; pp. 283-295.

18. Moscatelli, A.; Gagliardi, A.; Maneta-Peyret, L.; Bini, L.; Stroppa, N.; Onelli, E.; Landi, C.; Scali, M.; Idilli, A.I.; Moreau, P. Characterisation of detergent-insoluble membranes in pollen tubes of Nicotiana tabacum (L.). Biol. Open 2015, 4, 378-399. [CrossRef] [PubMed]

19. Laemmli, U.K. Cleavage of structural proteins during the assembly of the head of bacteriophage T4. Nature 1970, 227, 680-685. [CrossRef]

20. Sinha, P.; Poland, J.; Schnölzer, M.; Rabilloud, T. A new silver staining apparatus and procedure for matrix-assisted laser desorption/ionization-time of flight analysis of proteins after two-dimensional electrophoresis. Proteomics Int. Ed. 2001, 1, 835-840. [CrossRef]

21. Sotira, S.; Dell'Anno, M.; Caprarulo, V.; Hejna, M.; Pirrone, F.; Callegari, M.L.; Tucci, T.V.; Rossi, L. Effects of Tributyrin Supplementation on Growth Performance, Insulin, Blood Metabolites and Gut Microbiota in Weaned Piglets. Animals 2020, 10, 726. [CrossRef]

22. Zaninelli, M.; Rossi, L.; Costa, A.; Tangorra, F.; Agazzi, A.; Savoini, G. Monitoring of goats' health status by on-line analysis of milk electrical conductivity. Large Anim. Rev. 2015, 21, 81-86.

23. Dell'Anno, M.; Hejna, M.; Sotira, S.; Caprarulo, V.; Reggi, S.; Pilu, R.; Miragoli, F.; Callegari, M.L.; Panseri, S.; Rossi, L. Evaluation of leonardite as a feed additive on lipid metabolism and growth of weaned piglets. Anim. Feed Sci. Technol. 2020, 266, 114519. [CrossRef]

24. FAO; WHO. Health and nutritional properties of probiotics in food including powder milk with live lactic acid bacteria. Prevention 2001, 5, 1-10.

25. Muñoz-Provencio, D.; Llopis, M.; Antolín, M.; De Torres, I.; Guarner, F.; Pérez-Martínez, G.; Monedero, V. Adhesion proper-ties of Lactobacillus casei strains to resected intestinal fragments and components of the extracellular matrix. Arch. Microbiol. 2009, 191, 153-161. [CrossRef] [PubMed]

26. Śliżewska, K.; Chlebicz-Wójcik, A.; Nowak, A. Probiotic Properties of New Lactobacillus strains Intended to Be Used as Feed Additives for Monogastric Animals. In Probiotics and Antimicrobial Proteins; Springer: Berlin/Heidelberg, Germany, 2020; pp. 1-17.

27. Krausova, G.; Hyrslova, I.; Hynstova, I. In Vitro Evaluation of Adhesion Capacity, Hydrophobicity, and Auto-Aggregation of Newly Isolated Potential Probiotic Strains. Fermentation 2019, 5, 100. [CrossRef]

28. Rossi, L.; Vagni, S.; Polidori, C.; Alborali, G.L.; Baldi, A.; Dell'Orto, V. Experimental Induction of Escherichia coli Diarrhoea in Weaned Piglets. Open J. Veter.-Med. 2012, 2, 1-8. [CrossRef]

29. Rossi, L.; Pinotti, L.; Agazzi, A.; Dell'Orto, V.; Baldi, A. Plant bioreactors for the antigenic hook-associated flgK protein expression. Ital. J. Anim. Sci. 2014, 13, 2939. [CrossRef]

30. Rossi, L.; Dell'Orto, V.; Vagni, S.; Sala, V.; Reggi, S.; Baldi, A. Protective effect of oral administration of transgenic tobacco seeds against verocytotoxic Escherichia coli strain in piglets. Veter. Res. Commun. 2014, 38, 39-49. [CrossRef] [PubMed]

31. Tuo, Y.; Yu, H.; Ai, L.; Wu, Z.; Guo, B.; Chen, W. Aggregation and adhesion properties of 22 Lactobacillus strains. J. Dairy Sci. 2013, 96, 4252-4257. [CrossRef] [PubMed]

32. Reggi, S.; Giromini, C.; Dell'Anno, M.; Baldi, A.; Rebucci, R.; Rossi, L. In Vitro Digestion of Chestnut and Quebracho Tannin Extracts: Antimicrobial Effect, Antioxidant Capacity and Cytomodulatory Activity in Swine Intestinal IPEC-J2 Cells. Animals 2020, 10, 195. [CrossRef]

33. Vergauwen, H.; Tambuyzer, B.; Jennes, K.; DeGroote, J.; Wang, W.; De Smet, S.; Michiels, J.; Van Ginneken, C. Trolox and Ascorbic Acid Reduce Direct and Indirect Oxidative Stress in the IPEC-J2 Cells, an In Vitro Model for the Porcine Gastrointestinal Tract. PLoS ONE 2015, 10, e0120485. [CrossRef]

34. Brosnahan, A.J.; Brown, D.R. Porcine IPEC-J2 intestinal epithelial cells in microbiological investigations. Veter. Microbiol. 2012, 156, 229-237. [CrossRef] [PubMed]

35. Tallon, R.; Arias, S.; Bressollier, P.; Urdaci, M. Strain-and matrix-dependent adhesion of Lactobacillus plantarum is mediated by proteinaceous bacterial compounds. J. Appl. Microbiol. 2007, 102, 442-451. [CrossRef]

36. Lebeer, S.; Vanderleyden, J.; De Keersmaecker, S.C. Host interactions of probiotic bacterial surface molecules: Comparison with commensals and pathogens. Nat. Rev. Genet. 2010, 8, 171-184. [CrossRef]

37. Lähteinen, T.; Malinen, E.; Koort, J.M.; Mertaniemi-Hannus, U.; Hankimo, T.; Karikoski, N.; Pakkanen, S.; Laine, H.; Sillanpää, H.; Söderholm, H. Probiotic properties of Lactobacillus isolates originating from porcine intestine and feces. Anaerobe 2010, 16, 293-300. [CrossRef] [PubMed]

38. Hsueh, H.-Y.; Yueh, P.-Y.; Yu, B.; Zhao, X.; Liu, J.-R. Expression of Lactobacillus reuteri Pg4 Collagen-Binding Protein Gene in Lactobacillus casei ATCC 393 Increases Its Adhesion Ability to Caco-2 Cells. J. Agric. Food Chem. 2010, 58, 12182-12191. [CrossRef]

39. Minelli, E.B.; Benini, A.; Marzotto, M.; Sbarbati, A.; Ruzzenente, O.; Ferrario, R.; Hendriks, H.; Dellaglio, F. Assessment of novel probiotic Lactobacillus casei strains for the production of functional dairy foods. Int. Dairy J. 2004, 14, 723-736. [CrossRef] 
40. Guo, Z.; Wang, J.; Yan, L.; Chen, W.; Liu, X.-M.; Zhang, H.-P. In vitro comparison of probiotic properties of Lactobacillus casei Zhang, a potential new probiotic, with selected probiotic strains. LWT 2009, 42, 1640-1646. [CrossRef]

41. Wang, G.; Zhang, M.; Zhao, J.; Xia, Y.; Lai, P.F.-H.; Ai, L. A surface protein from Lactobacillus plantarum increases the adhe-sion of lactobacillus strains to human epithelial cells. Front. Microbiol. 2018, 9, 2858. [CrossRef] [PubMed]

42. Hynönen, U.; Palva, A. Lactobacillus surface layer proteins: Structure, function and applications. Appl. Microbiol. Biotechnol. 2013, 97, 5225-5243. [CrossRef]

43. Siezen, R.; Boekhorst, J.; Muscariello, L.; Molenaar, D.; Renckens, B.; Kleerebezem, M. Lactobacillus plantarum gene clusters encoding putative cell-surface protein complexes for carbohydrate utilization are conserved in specific gram-positive bacteria. BMC Genom. 2006, 7, 1-13. [CrossRef]

44. Pretzer, G.; Snel, J.; Molenaar, D.; Wiersma, A.; Bron, P.A.; Lambert, J.; de Vos, W.M.; van der Meer, R.; Smits, M.A.; Kleer-ebezem, M. Biodiversity-based identification and functional characterization of the mannose-specific adhesin of Lactobacillus plantarum. J. Bacteriol. 2005, 187, 6128-6136. [CrossRef] [PubMed]

45. Jensen, H.; Roos, S.; Jonsson, H.; Rud, I.; Grimmer, S.; Van Pijkeren, J.-P.; Britton, R.A.; Axelsson, L. Role of Lactobacillus reuteri cell and mucus-binding protein A (CmbA) in adhesion to intestinal epithelial cells and mucus in vitro. Microbiology 2014, 160, 671-681. [CrossRef] [PubMed]

46. Wang, B.; Wei, H.; Yuan, J.; Li, Q.; Li, Y.; Li, N.; Li, J. Identification of a Surface Protein from Lactobacillus reuteri JCM1081 That Adheres to Porcine Gastric Mucin and Human Enterocyte-Like HT-29 Cells. Curr. Microbiol. 2008, 57, 33-38. [CrossRef] [PubMed] 